Administrative Issues Journal: Connecting Education, Practice, and Research, Summer 2017, Vol. 7, No. 1: 70-83. DOI: 10.5929/2017.7.1.6

\title{
A Systems Theory approach to the District Central Office's role in school-level improvement
}

\author{
Jackie Mania-Singer, Ed.D. \\ Oklahoma State University
}

\begin{abstract}
This qualitative case study used General Systems Theory and social network analysis to explore the relationships between the members of a district central office and principals of elementary schools within an urban school district in the Midwest. Findings revealed sparse relationships between members of the district central office and principals, more opportunities for higher performing schools to participate in decision making, and few opportunities for all schools to provide feedback to the district, resulting in a centralized network structure that may inhibit the transfer of knowledge and communication, and ultimately, hinder school-level improvement efforts.
\end{abstract}

Keywords: systems theory, social network analysis, district central office, reform

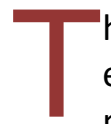

he past two decades have been marked by large-scale federal education reforms aimed at eliminating the achievement gap between subgroups and improving academic outcomes in the nation's lowest performing schools. The No Child Left Behind Act of 2001 (NCLB), the Race to the Top Fund, and the Elementary and Secondary Act (ESEA) Flexibility waiver increased accountability of districts and schools by instituting rigorous achievement targets, implementing high stakes testing in multiple subject areas, establishing sanctions as incentives for improvement, and in some states, ushering in sweeping legislative changes tying teacher evaluations to student performance and establishing steeper consequences for persistently failing schools (Elementary and Secondary Education Act, 2011; NCLB, 2001; Race to the Top Fund, 2009). In most cases, these reforms relied heavily on prescribed efforts related to curriculum, leadership, and personnel focused at the school level, placing increased pressure and urgency on principals and teachers working in already challenging conditions (Finnigan, 2010; Finnigan, 2012).

Ultimately, these efforts did not result in the intended outcomes. Arne Duncan highlighted these failures in a 2011 testimony before the House Committee on Education and the Workforce, admitting that "four out of five schools in American may not meet their goals under NCLB." Results of the NAEP Trends in Academic Progress (2012) show that although progress has been made in both reading and math for nine and 13 year olds since the first assessments were given in the 1970s, there has been no significant change 
in scores for 17 year olds, and scores for all grades in reading and math decreased or showed no significant change between 2013 and 2015 (The Nation's Report Card, 2015). Additionally, research on the effects of large-scale reform has found that schools that do exit the failing list are often doomed to return within a few years, and sanctions and other high-stakes incentives can have far reaching negative effects on students' academic experiences (Darling-Hammond, 2006; Mintrop \& Sunderman, 2009; Scott, 2008; Selwyn, 2007; Sunderman, 2006).

School improvement is a complex issue with many variables. Factors such as socioeconomic status, school leadership, teacher quality, and family involvement can affect a school's ability to meet performance standards (Beatty, 2007; Hargreaves \& Shirley, 2008; Hill \& Tyson, 2009; Sykes \& Dibner, 2009). Yet, recent national reforms, as well as their predecessors, IASA and Goals 2000, have consistently targeted specific low-performing groups or schools and focused financial and human capital support in those isolated areas (Goals 2000, 1994; IASA, 1994; NCLB, 2001, RTTT, 2009; ESEA, 2011). Research suggests that focusing on the larger context of schools instead of individual schools may be integral not only to understanding school-level improvement, but also in supporting schools in implementing and sustaining improvement efforts (Coburn, Choi, \& Mata, 2010; Daly \& Finnigan, 2010; Daly \& Finnigan, 2012; Fullan, Cuttress, \& Kilcher, 2009). These findings are of particular interest as states have been given the flexibility under the most recent large-scale federal education reform, the Every Student Succeeds Act (2015), to rethink accountability systems and establish differentiated reforms to better address the needs of the lowest performing schools.

\section{Problem Statement}

Comprehensive educational reform efforts of the last 20 years have invested billions of dollars in supplemental funding and incentivized the implementation of innovative improvement practices in our nation's schools (United States Department of Education, 2016). However, despite these reform efforts, districts and schools have experienced mixed results in student outcomes, resulting in what Fuller et al. (2007) referred to as "jagged mountain range, erratically moving up and down as tests are changed and proficiency bars are moved" (p. 268).

A possible explanation for the ineffective reform efforts is that school improvement initiatives have traditionally been implemented in a school-by-school approach and have placed little to no emphasis on the larger system in which these schools operate. One area of the system most often neglected in school reform efforts is the district central office. Traditionally viewed as the "popular scapegoat for perceived poor performance" (Smith \& Larimar, 2004, p. 735) and often overlooked as an agent of change, the district central office has historically served as a flow-through for large-scale reform funding and services (Honig, 2008). However, contemporary research on school improvement and reform increasingly supports including the district central office in reform efforts (Burch \& Spillane, 2004; Chrispeels, et al, 2008; Daly \& Finnigan, 2009; Finnigan \& Daly, 2012; Honig, 2003; Honig, 2008; Johnson \& Chrispeels, 2010). For example, Honig (2010) found when district central offices move beyond structural changes and transform the day-to-day work to focus on teaching and learning, the capacity for schools to improve is increased. Additionally, Burch and Spillane (2004), in their three-year study of central offices, found "mid-level 
managers have significant impact on how district reform policies are understood and acted on by school leaders" (p. 3). When managers broker information in a collaborative style, districts and schools successfully form communities of practice focused on instruction in which central office staff and school staff learn from each other and use expertise and experiences from all levels to successfully implement reform strategies (Burch \& Spillane, 2004).

\section{Purpose of the Study}

The purpose of this qualitative case study was to explore relationships between the district central office and higher and lower performing elementary schools through the lens of General Systems Theory and to identify what, if any, influence these relationships have on the ability of schools to implement and sustain reform efforts to improve student outcomes. Additionally, the method of Social Network Analysis (SNA) was used to quantify and create graphic representations of the relational ties between members of the district central office and school principals and the transfer of communication and knowledge across the system as improvement efforts were implemented.

\section{Research Questions}

Specifically, this study sought to answer the following questions:

1. In terms of General Systems Theory (GST), what types of relationships exist between the district central office and elementary schools in an urban school district?

2. What are the differences in the relationships, if any, between the district central office and higher performing and lower performing schools?

3. In what ways do the relationships between a school site and the district central office influence a school's ability to implement and sustain improvement efforts?

\section{Theoretical Framework}

General Systems Theory (GST) provides a framework for studying the interactions of the parts of systems such as school districts. In contrast to earlier theorists who advocated for bureaucratic or scientific management, Bertalanffy (1950) posited that organizations functioned more like biological systems than machines and recognized that relationships between parts of the system were vital to overall success. According to GST, assessing the patterns of these relationships is key to understanding the organization and the roles each part of the system plays (Bertalanffy, 1972).

Several key elements of system theory are applied when studying organizations. First, GST places emphasis on the structure of organizations as a series of interrelated subsystems (Bertalanffy, 1950; Patton, 2006; Patton \& McMahon, 2006) in which each subsystem is interdependent on the other. Second, GST views all organizations as "open systems" or systems that are constantly influenced by and placing influence on the larger environment (Bertalanffy, 1950). Third, these interrelated subsystems operate in a continuous

MANIA-SINGER / DOI: 10.5929/2017.7.1.6 
feedback loop. This loop consists of inputs, internal transformation, outputs, and recursive feedback (Bertalanffy, 1950; Patton, 2006). The feedback from each part of the system is used to reinforce (if positive) or correct (if negative) the inputs the part of the system will then receive (Bertalanffy, 1972). Success within a system, then, depends on dynamic interactions during this cyclical process (Bertalanffy, 1950).

For the purposes of this study, I was interested in how the inputs (resources, policies, practices, communication, and support) from the district central office influenced the internal transformation (implementation of school improvement reforms) and outputs (student academic outcomes) in higher and lower performing elementary schools. I was particularly interested in the formal and informal opportunities available for elementary school principals to provide feedback to the district central office and the process the district central office used to reinforce or correct future inputs to the schools based on this feedback.

Social network analysis (SNA) provides a conceptual model by which to visualize and quantify the interactions within a system and a lens through which to view the capacity of the district to support school level improvement (Borgatti \& Ofen, 2010; Scott, 2000; Wasserman \& Faust, 1994). In social network analysis, relational data is presented as a set of nodes and ties, and the web of relationships created by the interconnecting nodes and ties is referred to as a sociogram (Borgatti \& Ofem, 2010; Scott, 2000). The main focus of SNA is to view all the nodes and ties as a whole instead of in isolation. Just as each node is important to the overall analysis, the position of the nodes, the number of connections, and the structure of the resulting sociogram are all important in determining the opportunities and constraints within the network (Borgatti \& Ofem, 2010).

According to Finnigan and Daly (2012), "the type, quality, and structure of relationships matter to a collective effort to improve" (p. 45). Social network analysis can be used to measure the centrality, density, and reciprocity of relationships. In social network analysis, centrality refers to how central an actor is in the network. It measures the number of ties an actor has and the distance between those actors. An actor with a higher centrality value may have more influence or power in a network because he/she has more access to information or resources and more opportunities to influence others in the network (Cross \& Parker, 2004; Prell, 2012). Density shows how cohesive a network is by measuring the percentage of ties that are present in the network as compared to all the possible ties that could be present in the network (Cross \& Parker, 2004; Prell, 2012). A network with a higher density has a higher number of ties between actors, and a network with a lower density has fewer ties between actors. Reciprocity indicates the mutual nature of a tie between actors (Cross \& Parker, 2004). If a connection in a network is reciprocal, it means that both actors identified a relationship to one another. The higher the reciprocity value, the more two-way relationships are present (Wasserman \& Faust, 1994). Together, these measures of centrality, density, and reciprocity explained the importance of individual actors, the closeness of the actors, and the direction of the relationships within the networks in this study (Wasserman \& Faust, 1994).

Social network analysis is also used to identify the types of relationships that exist between actors in a system. Networks consist of both instrumental and expressive ties (Lin, 1999). Instrumental ties refer to the technical or tangible relationships between members of a network. These are most often work-related

MANIA-SINGER / DOI: 10.5929/2017.7.1.6 
relationships (Finnigan \& Daly, 2012; Lin, 1999). Expressive ties refer to the psychological or behavioral supports or social interactions between members of the network. These types of relationships include sharing feelings, expressing stressors, or sharing resources related to physical or mental well-being (Lin, 1999). In effective systems, both types of ties are present and constantly influencing and acting with each other. Research also shows that instrumental relationships can eventually evolve into expressive relationships as trust is built (Lin, 1999). According to Finnigan and Daly (2012), a high number of expressive relationships based on trust and social interaction within a district has a positive effect on culture and overall improvement in the district.

\section{Methods}

For this study, a case study design that draws on the methodological approach of social network analysis (SNA) was chosen to tell the story of schools within an urban district attempting to implement reforms under increasing state and federal pressure and to share the stories of the participants living this experience. The case study design allowed multiple data sources to be used to provide a more comprehensive description of the case, as well as develop a deeper understanding of the phenomena being studied (Patton, 2002). For the purpose of this case study, SNA surveys and sociograms were used in conjunction with qualitative methods of in-depth interview, observation, and document review to create a detailed visual picture and narrative story of the relationships between the members of the district central office and principals of elementary schools in an urban school district.

\section{Context of the Study}

Johnson Public Schools is an urban school district in the Midwest serving over 30,000 students. Of the students who attend these schools, approximately $89 \%$ are eligible for Free/Reduced lunch, and over 12,000 are identified as English Language Learners. Johnson Public Schools is a majority minority district, with over $80 \%$ of students identifying as Hispanic, African American, Native American, Asian or Pacific Islander. The district faces many of the same challenges as other urban schools. In the last year of NCLB identifications, 2011-2012, Johnson was named a District in Improvement in Year 2, and in subsequent years after the state's adoption of the new accountability system under the ESEA Flexibility Waiver, Johnson scored a D and an F, respectively. Academically, Johnson's ACT average of 18 is lower than the state average of 20 , and the district repeatedly scores lower on state proficiency exams than the state average.

Within the district, elementary schools vary in size, population, and performance. The elementary schools range in size from the smallest site, 200 PK-6 students, to the largest site, 1100 PK-6 students. Depending on the area of the city in which the school site is located, the population can also vary from a site with $97 \%$ minority students and a Free and Reduced Lunch rate of $100 \%$ to a site with $52 \%$ minority students and a Free and Reduced Lunch Rate of $40 \%$. Although almost all schools report a yearly attendance rate of over $90 \%$, the percentage of students scoring proficient in reading or math ranged from a low of $11 \%$ of students to a high of $89 \%$ of students in 2013-2014. Additionally, in 2012-2013 only seven of these schools earned an A or B on the State's A-F report card, while the majority of schools received Ds or Fs. 
These differences present each elementary school with unique challenges and needs as they attempt to implement reform efforts to improve student achievement.

\section{Data Collection}

The data for this case study came from many sources, including SNA name generator surveys and sociograms, interviews, observations, and document review. SNA surveys were administered to 35 participants at the district central office and 56 elementary site principals, with a response rate of $25 \%$. A free choice survey through which participants identified relationships with as many members of elementary administration or district central office as possible was used, and participants were not limited in the number of responses they could give (Scott, 2000). This type of survey was chosen due to the potential size of a pre-populated survey and based on existing research on SNA surveys. Scott (2000) stated that free choice surveys increase response rates of the participants and provide a more comprehensive picture of the resulting relationships. Each survey elicited participant responses to relationships in the areas of best practices, data, decision-making, communication, professional grown, personal issues, and time spent outside of work. These focus areas were guided by the study research questions and contemporary SNA research in education (Daly \& Finnigan, 2009; Daly \& Finnigan, 2012; Finnigan \& Daly, 2012). In addition to the SNA survey, 11 interviews with members of the district central office and site principals and one interview with a teacher were conducted. Data collection also included multiple observations at district-level meetings and on-site at two elementary schools. District and site documents including district planning documents, meeting agendas, committee member lists, and additional written interactions between member of the district central office and elementary school sites were reviewed to triangulate data and provide deeper understanding of the relationships within the district.

\section{Data Analysis}

Data analysis was conducted through a two-phase process: 1) analysis of surveys using traditional SNA methods and 2) content analysis of the interviews, observations, and documents in addition to the resulting sociograms. The two phases of analysis overlapped chronologically and analysis occurred simultaneously with data collection.

SNA Survey Analysis. To analyze the returned surveys, the survey data was entered into UCINET, a web-based social network analysis software, and matrix of relationships for each of the survey questions was created (Borgatti, Everett, \& Freeman, 2002). This resulted in seven matrices representing the relationships between the district central office members and the elementary principals. The matrices generated by UCINET were then entered into Netdraw, an online program for creating visual representations of network data, to create sociograms for each matrix (Borgatti, 2002). The response rate of $25 \%$ was much lower than the $70 \%$ threshold recommended by Scott (2000.) Because of this rate, the networks were incomplete for a comprehensive picture of the entire system; however, the sociograms were used as a qualitative artifact, providing triangulating data for the interviews, observations, and documents. The resulting sociograms were also used to guide follow-up interview questions. 
Content Analysis. To analyze the qualitative data, the content analysis process was adapted for this study (Merriam, 1988, Yin, 2009). The content analysis process involved organizing and reviewing the data to become familiar with the dataset and find any gaps in the data; open coding of interview transcripts, notes from field observations and meetings, documents, and sociograms; identifying patterns or categories; and reflectively reading the recurring codes to construct themes. The themes were then tested against other data sets. Peer debriefing, referential adequacy, and triangulation of data sources provided trustworthiness and strengthened validity. General Systems Theory and social network analysis were applied to provide structure and language for the analysis and interpretation of data.

\section{Findings}

\section{Types of Relationships}

One key focus of SNA is to view all the nodes and ties in a network as a whole instead of in isolation. Data from this study indicated there were few relationships that existed between members of the district central office and elementary school principals in any of the seven areas studied: best practices, data, decision-making, communication, professional growth, personal issues and social interaction outside of work. Two of the principals interviewed provided the following descriptions of their interactions with the district. Principal 14 (P14) stated

There are trainings, but I would not say they relate directly to what I do...a lot of the trainings are for a new program or a new software system, not what I would consider best practices. You know? We don't even have a training for finance, and this last year, they actually improved that by giving us a one hour PowerPoint at one of our meetings. It's kinda laughable, but that's actually a huge improvement from nothing.

P45 also had a difficult time answering the question, and finally responded, "If there are any [supports or programs], I don't know what they are. I find everything for myself. I would say any attempts are more informal."

The teacher interviewed for this study summed up his relationships with members of the district central office in this way: "To be honest, I wouldn't be able to put any faces with names at the district level."

In this urban district, the relationships between members of the district central office and principals seem to be more often instrumental, or based on basic professional information, and less expressive; very little social interaction occurred between members of the district central office and elementary school principals. No participant interviewed stated that there were opportunities for members of the district central office and principals to interact in a social setting. The social interaction that was reported was described as informal or arose spontaneously before and after district meetings.

Additional analysis showed that most of the relationships between members of the district central office and principals were unreciprocated. One of the major themes found in the data regarding relationships in 
this district is that principals sought out information from members of the district central office at a much higher rate than members of the district central office sought information from principals. The data show that in the areas included in this study, the members of the district central office most often provided information to the principals, without including them in the decision-making process. According to D0204,

We are not really involved with the schools' data collection. What we do is analyze the data and provide it to the [elementary] directors. We don't have much contact with the schools as far as the analysis part.

Additionally, data from interviews also indicated a lack of opportunities for principals to provide feedback to the district central office. Principal interviews and document review indicated few principals present on committees, infrequent committee meetings, and committees comprised of majority members of the district central office. Principals interviewed expressed uncertainty of the effectiveness of the committees citing lack of connection between work done in committees and resulting recommendations to the larger district. One principal, P38, identified as a principal of one of the lowest performing schools, reported in an interview that he has never been on a committee and was unsure even how to be involved in decision making stating, "I don't know [how to join a committee]. I think they must just pick people for them." Interview data revealed there was no formal process for principals to give feedback. Although opportunities for principals to sit on committees appeared to exist, only one interviewed participant from the district central office could articulate how principals were chosen for those committees, and one of the interviewees admitted that she just did not know how principals were selected.

\section{Differences in Relationships Among Schools}

Analysis of the data in terms of GST revealed there are differences in the relationships between the members of the district central office and elementary principals of higher and lower performing schools. In this urban district, principals of high performing schools receive more support and resources (input) from the members of the district central office than do principals of low performing schools and have more opportunity to provide feedback to the district central office than do principals of low performing schools.

During the interview, D0204 stated that his department specifically chose principals for committees based on school performance, and principals of higher performing schools interviewed indicated more involvement at the district level than did principals of low performing schools. Data analysis also showed that principals of high performing schools were more often included on committees at the district level or were involved in more two-way relationships with members of the district central office. Of the committee member lists analyzed, all included a majority of principals from higher performing schools. Additionally, one principal's name appeared on all major committees, P06, the principal of the highest performing school in the district. These opportunities and relationship networks afford the principals of high performing schools more opportunity to provide feedback to members of the district central office, thereby potentially impacting future input and influence that goes back into the schools.

MANIA-SINGER / DOI: 10.5929/2017.7.1.6 


\section{Influence on Improvement Efforts}

According to GST, systems need appropriate and adequate input and influence to make the internal transformation necessary to produce the desired output and meet intended goals. As part of this process, feedback is integral to providing information necessary to the larger system so that future input and influence can better meet the needs of each part of the system. Sustained system change depends on this cyclical process.

In this district, the connections necessary to sustain this process were not evident. Because of the lack of connectivity, it can be reasoned that any input the district central office may provide to the schools is being received by only a small population. This finding was supported by the interviews with the principals. P38 stated that she felt "out of the loop on communication," and P19 shared, "there are some things we need to know that we don't know about."

Analysis also showed that there were discrepancies between what the members of the district central office in JPS believe is being provided in terms of influence and what the principals reported as being provided. According to interviews and review of district planning documents, many members of the district central office believed that they were providing opportunity for feedback during formal planning and decision-making processes. Both the Title I Plan and the District Comprehensive Plan referred to a structured planning process that was reportedly used at both the district and school levels as well as formal communication processes that were designed to ensure all stakeholders were informed of decisions and supported in implementing the decisions. However, some interview participants claimed the planning and decision-making processes in the district were, in reality, more informal and unstructured. Comments that support this finding include
P14: "It's all been by trial and error."
P38: "I do talk to other principals, but it is informal."
P45: "I would say any attempts are more informal."
P19: "It is an informal process."
D0204: "It was something ad hoc."
D0308: "There's just informal communication that takes place..."
D0314: “...sometimes during conversation or when principals stop by...”

Other discrepancies in perception of the members of the district central office and the reality of the principals were seen in the areas of data and communication. During the interviews, participants from district central office stated they placed heavy emphasis on data and encouraged school sites to use data to make decisions and improve student learning. However, principals interviewed reported receiving little more than spreadsheets of raw data from the district and spending their own time trying to make sense of the data to transform it into a format teachers can use. Study participants from the district central 
office also expressed pride in the formal communication sent to the sites through newsletters and email distribution lists. However, although principals interviewed indicated email was the primary means of communication within the district, they also reported the newsletters and emails were ineffective. Specifically, P45 reported that newsletters were "regular for a time, but departments just stopped sending them," and P14 claimed that principals received so many emails that "it was difficult to address each email and ensure all important information was read."

\section{Discussion}

In terms of social network analysis, the networks in the district central office and schools in this study revealed sparse connections, a low number of reciprocated relationships, and a high number of isolated actors. The low density and lack of reciprocity indicate ineffective transfer of knowledge and information across the system and less sharing of ideas and feedback between the actors. Additionally, the relationships in this district were more often instrumental; that is, they were centered on areas most closely related to everyday work. There were very few expressive relationships revealed in this study, indicating a possible lack of trust or a culture in which members do not feel free to share personal information or socially interact with colleagues.

Concerning General Systems Theory, the findings of this study suggest that the processes indicative of effective systems - a cyclical process of inputs, internal transformation, outputs, and recursive feedbackwere not evident in this district. Although resources and supports (inputs) were provided to schools, discrepancies existed between what the district believed it was providing to schools and what the principals perceived was provided, or more importantly, what the principals stated was needed to implement improvement efforts. This discrepancy of perception versus reality may impact the district's ability to effectively provide input and influence during the phase of internal transformation. Because the district perceived that it was offering adequate and appropriate input and influence, there seemed to be little motivation to change the resources and support provided to schools. Additionally, because information in this district was shared more informally, it is quite possible that most members of the district central office and elementary principals were unaware of the resources and support available because they were unsure how to access it.

For all schools in the system to succeed, high and low performing schools need differentiated supports and services based on feedback. Johnson Public Schools included in both its District Improvement Plan (DIP) and Title I Plan (TIP) that the district provides "intensive support" for its lowest performing schools. However, the data from this study did not support the claim of intensive support for lower performing schools. Rather, this study found principals of higher performing schools received more support from and had more opportunity to provide feedback to the district central office. It also appeared the district central office provided the same services and supports to all elementary schools in Johnson Public Schools, but higher performing schools may experience increased benefit. Lack of opportunity for lower performing schools to provide feedback means that lower performing schools within Johnson Public Schools are missing a key component in enacting transformative change. With few feedback loops to inform members of the district central office, the inputs and influence from the district may continue to be a mismatch for 
the needs of the schools. This finding suggests if the relationships between the members of the district central office and the schools do not undergo fundamental change, higher performing schools could continue performing at high levels, while low performing schools remain low performing.

\section{Implications}

\section{Implications for Theory}

The implications for theory include the use of two frameworks, General Systems Theory and social network analysis, to explore the relationships within a school district. In this study, the frameworks proved to be complimentary. This study, however, only involved one urban school district, and additional research is necessary to determine if the use of the frameworks is successful in other contexts. This study also demonstrated how social network analysis can be used to "understand how the underlying network of interactions within and organization may affect efforts at change" (Daly \& Finnigan, 2009). Other frameworks that could also that could provide additional perspective on how the interactions within a school district affect systemwide change are organizational learning theory, which explores the decision making and problem solving processes in organizations to determine and organization's ability to achieve double-loop learning for fundamental change (Argyris, 1993), and transformational leadership which promotes individual and collective growth while relying on strong, positive relationships between leaders and other member of the system so as to motivate and empower all to attain systemwide change (Leithwood, 1994).

\section{Implications for Research}

Much of the current literature on district central offices focuses on specific actions district central offices enact to inhibit school improvement efforts or improving efficiency of services to schools (Fullan, 2009; Meier \& Bohte, 2000; Smith \& Larimar, 2004). A research gap exists on practical steps districts can enact for successful transformation (Honig, 2010). Additionally, research on district office transformation often focuses on large urban districts who have been consistently lower performing (Daly \& Finnigan, 2009; Daly \& Finnigan, 2010; Daly \& Finnigan, 2012). There is much to learn about relationships between district central offices and schools in higher performing districts and in other types of school settings including smaller districts, rural districts, and charter schools. Additionally, as relationships in organizations can evolve over time (Lin, 1999), future research could examine relationships within a district over a period of years.

\section{Implications for Practice}

This study provided insight on how information and knowledge is transferred between the district central office and schools and highlights the practices, or lack thereof, that constrain implementation of reform efforts at the school level. The findings suggest greater attempts must be made at the district level to create formal structures for communication, sharing of information and exchange of ideas. Districts should also pay greater attention to facilitating collaboration among members of the district and the 
sharing of expertise not only from the district to the schools, but also from the schools to the district central office. Perhaps most importantly, this study emphasizes importance of formal structures for receiving feedback from all schools, but specifically the lower performing schools who often feel more isolated (Finnigan, 2010; Finnigan, 2012). Once feedback is received, the district should make a coordinated effort to reinforce or correct future actions to better meet the needs of schools.

\section{Limitations}

This study presents limitations that should be addressed. First, the study was conducted in one urban school district. Due to the nature of qualitative case study, findings are related to this particular district and cannot be generalized across a larger population. Another limitation involves the context of the district. The district has a relatively high turnover rate for superintendents, district central office leadership, and principals. The nature of how this turnover influences relationships in this district was not addressed in this study. Finally, this study provides a narrative based on a small number of participants. Not all members of the district central office or elementary school principals chose to participate. The sample size, demographics, and self-selection of the population could have skewed the findings. It is unknown how the relationships and sociograms would have differed given a larger population. Additional research with a larger population of participants is needed to gain a deeper understanding of the entire network.

References

Argyris, C. (1993). Education for leading-learning. Organizational Dynamics, 21(3), 5-17.

Beatty, B. (2007). Going through the emotions: Leadership that gets to the heart of school renewal. Australian Journal of Education, 51(3), 328-340.

Bertalanffy, L.V. (1950 Aug). An outline of general systems theory. The British Journal for the Philosophy of Science, 1(2), 134-165. Retrieved from http://www.jstor.org/stable/685808

Bertalanffy, L. V. (1972). The history and status of general systems theory. The Academy of Management Journal, 15(4), 407-426. Retrieved from http://www.jstor.org/stable/255139

Borgotti, S. P. \& Ofem, B. (2010). Overview: Social network theory and analysis. In A. Daly (Ed.), Social Network theory and educational change (p. 17-29). Cambridge, MA: Harvard Education Press.

Borgatti, S. P. (2002). NetDraw Network Visualization. Analytic Technologies. Harvard, MA.

Borgatti, S. P., Everett, M. G., \& Freeman, L. C. 2002. Ucinet 6 for Windows: Software for Social Network Analysis. Harvard, MA: Analytic Technologies

Burch, P., \& Spillane, J. (2004). Leading from the middle: Mid-level district staff and instructional improvement. Chicago, IL: Cross City Campaign for Urban School Reform.

Chrispeels, J. H., Burke, P. H., Johnson, P., \& Daly, A. (2008). Aligning mental models of district and school leadership teams for reform coherence. Education and Urban Society, 40(6), 730-750.

MANIA-SINGER / DOI: 10.5929/2017.7.1.6 
Coburn, C. E., Choi, L., and Mata, W. (2010). "I would go to her because her mind is math": Network formation in the context of district-based mathematics reform. In A. Daly (Ed.) Social network theory and educational change. Cambridge, MA: Harvard Education Press.

Cross, R., \& Parker, A. (2004). The hidden power of social networks: Understanding how the work really gets done in organizations. Boston, MA: Harvard Business School Press.

Daly, A.J., \& Finnigan, K. (2009). A bridge between worlds: Understanding network structure to understand change strategy. Journal of Educational Change, 11,111-138. doi: 10.1007/s10833009-9102-5

Daly, A.J., \& Finnigan, K. (2010). The ebb and flow of social network ties between district leaders under high-stake accountability. American Educational Research Journal, 48(1), 39-79. doi: 10.3102/0002831210368990

Daly, A.J., \& Finnigan, K. (2012). Exploring the space between: Social networks, trust, and urban school leaders. Journal of School Leadership, 22, 493-430.

Darling-Hammond, L. (2006). No Child Left Behind and high school reform. Harvard Educational Review, 76(4), 642-667.

Finnigan, K., \& Daly, A. (2010). Learning at a system Level: Ties between principals of low performing schools and central office leaders. In A. Daly (Ed.), Social network theory and educational change (pp. 179-195). Cambridge, MA: Harvard Education Press.

Finnigan, K. S. (2010). Principal leadership and teacher motivation under high-stakes accountability policies. Leadership and Policy in Schools, 9(2), 161-189.

Finnigan, K. S. (2012). Principal leadership in low performing schools: A closer look through the eyes of teachers. Education and Urban Society, 44(2), 183-202. doi: 10.1177/0013124511431570

Finnigan, K. S, \& Daly, A., (2012). Mind the gap: Organizational learning and improvement in an underperforming urban system. American Journal of Education, 119(1), 41-71.

Fullan, M., Cuttress, C., \& Kilcher, A. (2009). 8 forces for leaders of change. In M. Fullan (Ed.) The challenge of change: Start school improvement now! (pp. 9- 20). Thousand Oaks, CA: Corwin Press

Fuller, B., Wright, J., Gesicki, K., \& Kang, E. (2007). Gauging growth: How to judge No Child Left Behind? American Educational Research Association, 36(5), 268-278.

Goals 2000: Educate America Act. P.L. 103-227, 108 Stat. 125. (1994)

Hargreaves, A., \& Shirley, D. (2008, October). Beyond standardization: Powerful new principles for improvement. Phi Delta Kappan.

Hill, N. E., \& Tyson, D.F. (2009). Parent involvement in middle school: A meta-analytic assessment of the strategies that promote achievement. Developmental Psychology, 45(3), 740-763.

MANIA-SINGER / DOI: 10.5929/2017.7.1.6 
Honig, M. I. (2003). Building policy from practice: District central office administrator's roles and capacity for implementing collaborative education policy. Educational Administration Quarterly, 39(3), 292338.

Honig, M., \& Copland, M. (2008). Reinventing district central offices to expand student learning. Issue Brief for The Center for Comprehensive School Reform and Improvement. Retrieved from http://depts.washington.edu/ctpmail/PDFs/S2-CentralAdmin-04-2010.pdf

The Improving America's Schools Act of 1994. (1994). P.L. 103-382; 108 Stat. 3518.

Johnson, P. E., \& Chrispeels, J. H. (2010). Linking the central office and its schools for reform. Educational Administration Quarterly, 46(5), 738-775.

Lin, N. (1999). Building a network theory of social capital. Connections, 22(1), 28-51.

Leithwood, K. (1994). Leadership for school restructuring. Educational Administration Quarterly, 30(4), 498-518.

Merriam, S. B. (1988). Case study research in education: A qualitative approach. San Francisco, CA: JosseyBass Publishers.

Mintrop, H., \& Sunderman, G. L. (2009). Why high stakes accountability sounds good but doesn't workand why we keep on doing it anyway. Los Angeles, CA: The Civil Rights Project/Proyecto Derechos Civiles at UCLA.

National Center for Educational Statistics. (2016). The nation's report card: 105 mathematics \& reading assessments. Retrieved from https://www.nationsreportcard.gov/reading math 2015/\# ?grade $=4$

National Center for Educational Statistics. (2013). NAEP 2012: Trends in academic progress. Retrieved from http://nces.ed.gov/nationsreportcard/subject/publications/main2012/pdf/2013456.pdf

No Child Left Behind Act of 2001, 20 U.S.C. § 6319 (2001).

Patton, M. Q. (2002). Qualitative research and evaluation methods. (3rd ed). Thousand Oaks, CA: Sage Publications, Inc.

Prell, C. (2012). Social network analysis: History, theory, and methodology. Thousand Oaks, CA: SAGE Publications.

Race to the Top Act of 2011, H.R. $1532-112^{\text {th }}$ Congress (2011).

Scott, J. (2000). Social network analysis: A handbook. Thousand Oaks, CA: SAGE Publications.

Selwyn, D. (2007). Highly quantified teachers: NCLB and teacher education. Journal of Teacher Education, 58(2), 124-137. doi: 10.1177/0022487106297842

Smith, K., \& Larimar, C. (2004). A mixed relationship: Bureaucracy and school performance. Public Administration Review. 64(6), 728-736.

MANIA-SINGER / DOI: 10.5929/2017.7.1.6 
Sunderman, G. L. (2006). The unraveling of No Child Left Behind: How negotiated changes transform the law. Cambridge, MA: The Civil Rights Project at Harvard University.

Sykes, G., \& Dibner, K. (2009). Improve Teaching Quality with Aggressive Support. Phi Delta Kappan, 90(8), 588-591.

United States Department of Education. (2012). The ESEA Flexibility Waiver Guidance. Retrieved from http://www.ed.gov/esea/flexibility

Wasserman, S., \& Faust, K. (1994). Social network analysis: Methods and applications. New York, NY: Cambridge UP.

Winning the Future of Education, 112th Congress. (2011) (testimony of Arne Duncan). Retrieved from http://www.ed.gov/news/speeches/winning-future-education-responsibility-reform-and-results

Yin, R. K. (2009). Case study research: Design and methods (4 ${ }^{\text {th }}$ edition). Thousand Oaks, CA: Sage Publications, Inc.

\section{About the Author}

Jackie Mania-Singer, Ed.D. (Jackie.mania@okstate.edu) is a visiting Assistant Professor of School Administration at Oklahoma State University. She has experience as a K-12 teacher and administrator, as well as a state-level director. She has researched and presented on educational issues related to curriculum studies, action research, and principal leadership. Her research interests include social network analysis, district central office transformation, and education reform. 